\title{
Impact of repeated ivermectin treatments against onchocerciasis on the transmission of loiasis: an entomologic evaluation in central Cameroon
}

Marc K Kouam ${ }^{1,2}$, Jules B Tchatchueng-Mbougua' ${ }^{1}$, Maurice Demanou ${ }^{3}$, Michel Boussinesq ${ }^{4,5}$,

Sébastien DS Pion ${ }^{1,4,5}$ and Joseph Kamgno ${ }^{1,6^{*}}$

\begin{abstract}
Background: Annual community-directed treatment with ivermectin (CDTI) have been carried out since 1999 in the Lekie division (central region of Cameroon where most cases of Loa-related post ivermectin severe adverse events were reported) as part of the joined activities of the African Programme for Onchocerciasis Control (APOC) and Mectizan ${ }^{\circledast}$ Donation Program (MDP). As large-scale administration of ivermetine was demonstrated to be an efficient means to control loiasis transmission, it was hypothesized that CDTI would have lowered or halted the transmission of Loa loa in the Lekie division after 13 years of annual drug administration, indicating a possible reduction in the occurrence of Loa-related post-ivermectin severe adverse events.
\end{abstract}

Methods: A 4-month entomologic study was carried out from March to June 2012 in the Lekie division to evaluate the impact of 13 years of CDTI on the transmission of L. loa whose baseline data were recorded in 1999-2000.

Results: There was a significant reduction in the infection rate for Chrysops silacea and C. dimidiata from 6.8 and 9\% in 1999-2000 to 3 and 3.6\% in 2012, respectively. The differences in the infective rate (IR) (percentage of flies harboring head L3 larvae), potential infective rate (PIR) (percentage of flies bearing L3 larvae), mean head L3 larvae load (MHL3) (average L3 per infective fly) and mean fly L3 larvae load (MFL3) (average L3 per potentially infective fly) for both C. silacea and C. dimidiata were not significantly different between the two investigation periods. The biting density (BD) was almost three-fold higher in 2012 for C. silacea but not for C. dimidiata. The transmission potential (TP) which is a function of the $\mathrm{BD}$, was higher in the present study than in the baseline investigation for each species.

Conclusion: The infection rate remaining high, the high TP and the stability observed in the IR, PIR, MHL3 and MFL3 after 13 years of CDTI suggest that transmission of $L$. loa is still active. This is an indication that the risk of occurrence of severe adverse events such as fatal encephalopathies is still present, especially for heavily microfilaria-loaded people taken ivermectin for the first time.

Keywords: CDTI, Entomologic indices, C. silacea, C. dimidiata, Loiasis, Cameroon

\footnotetext{
*Correspondence: kamgno@crfilmt.org

${ }^{1}$ Filariases and other Tropical Diseases Research Center (CRFilMT), P.O. Box 5797, Yaoundé, Cameroon

${ }^{6}$ Faculty of Medicine and Biomedical Sciences University of Yaoundé I, P.O.

Box 1364, Yaoundé, Cameroon

Full list of author information is available at the end of the article
} 


\section{Background}

Control programs against onchocerciasis and lymphatic filariasis are based on mass treatment with ivermectin (IVM) and a combination of IVM and albendazole, respectively. Since 1991, serious adverse events (SAEs), including fatal cases of encephalopathy have been recorded in areas where onchocerciasis and loiasis (Loa loa filariasis) are co-endemic. In the following years, it has been shown that these accidents occur in individuals presenting a $L$. loa microfilaremia exceeding 30,000 microfilariae per milliliter of blood $(\mathrm{mf} / \mathrm{ml})$ [1-4]. L. loa is transmitted by tabanids belonging to the genus Chrysops and is highly endemic in forested regions as well as in some savanna areas of west and central Africa [5,6]. In 2000, the African Programme for Onchocerciasis Control (APOC) and the Mectizan ${ }^{\circ}$ Donation Program (MDP) set up a specific surveillance system in areas where onchocerciasis and loiasis are co-endemic, for an early detection and management of SAEs $[7,8]$.

This strategy has been successful in terms of reduction of lethality rate, but is somewhat costly to put in place [9]. Thus, the issue has been raised as to whether it should be maintained for as long as the communitydirected treatment with IVM (CDTI) continues. Indeed, as IVM brings about a long-lasting decrease in Loa microfilaremia [10,11], almost all those individuals who have received the drug at least once are no longer at risk of developing a SAE. This is supported by the fact that more than $90 \%$ of the SAEs occur after a first treatment with IVM [12]. During the subsequent CDTIs, the surveillance system has to be maintained to detect and manage SAEs only in those adults who have never taken the drug for various reasons (refusals, migrants from untreated areas, repeated contra-indications) and in all children reaching the age of 5 for whom IVM was formerly contra-indicated. Maintaining the system is justified by the fact that during the first rounds of CDTI, the situation of these untreated persons regarding their infection with $L$. loa remains probably unchanged. However, on a longer term, this is probably not the case because the decrease in the microfilarial reservoir following mass IVM treatment might also reduce the number of parasites ingested and retransmitted by the vectors, and thus have a beneficial indirect effect on the total population, including those who have never taken the drug. Actually, this reduction in the transmission of L. loa in the CDTI area would have two effects. First, in uninfected or little infected children the reduction in the number of incoming infective larvae (L3) would have an impact on the number of adult worms developing, which might prevent them to present a high microfilaremia. Second, in adult subjects who already harbour adult worms, and do not receive the drug, it would lead to a slow reduction in the microfilaremia due to the fact that the number of worms dying naturally would exceed the number of new parasites. However, in the latter case, the time after which this effect would occur is not known because one lacks information on the mean lifespan of adult $L$. loa - the only information available is on its maximum, which could be 20 years [13].

The objective of the present study was to evaluate the impact of repeated annual IVM treatment on the intensity of transmission of loiasis, and thus on the possible reduction in the risk of SAEs in the untreated population. Such an evaluation can be made by two means: either by comparing the microfilarial loads found in untreated children before and after the implementation of the program, as it has been done for onchocerciasis [14], or by comparing the intensity of infection in the Chrysops vectors. Such an entomologic approach has been used to evaluate the impact of three monthly treatments on Loa transmission [15], but never that of annual CDTI. Consequently, an entomologic study was conducted in a village of the Lekie division (a division of the central region of Cameroon where most of the cases of SAEs recorded in the country occurred) where the transmission of loiasis had been characterized in detail in 1999-2000 at the early beginning of CDTI.

\section{Methods}

\section{Study area}

This site (Figure 1) was already described in detail by Demanou et al. [16]. Brievely, Kokodo $\left(4^{\circ} 12^{\prime} \mathrm{N}, 11^{\circ} 18^{\prime} \mathrm{E}\right)$ is located in the Elig Mfomo subdivision, about $70 \mathrm{~km}$ north-west of Yaounde, in an area of semi-degraded forest. Elig Mfomo is within the Lekie division where most cases of SAEs have been documented $[4,16]$. The climate is equatorial with four seasons comprising two rainy seasons from September to mid-November, and from mid-March to June. The annual rainfall ranges between 1600 and $2000 \mathrm{~mm}$, and the mean annual temperature is $25^{\circ} \mathrm{C}$. In 2010, the total population in Kokodo was 1615 persons.

No survey on onchocerciasis has ever been conducted in Kokodo. However, the parasitologic surveys and rapid epidemiologic assessments (based on the prevalence of nodules) performed in the 1990s in neighboring villages, have shown that the area is at least mesoendemic for onchocerciasis (Boussinesq, unpublished data).

\section{Previous studies on loiasis in Kokodo}

In January 1996, the village was included in a study aiming at identifying the risk factors associated with post-IVM SAEs [4]. Detailed data on Kokodo currently presented, though part of the study by Gardon et al. [4] in the Lekie division, were not previously published. A total of 453 persons aged 15 years and above participated in the study. All individuals were first asked 


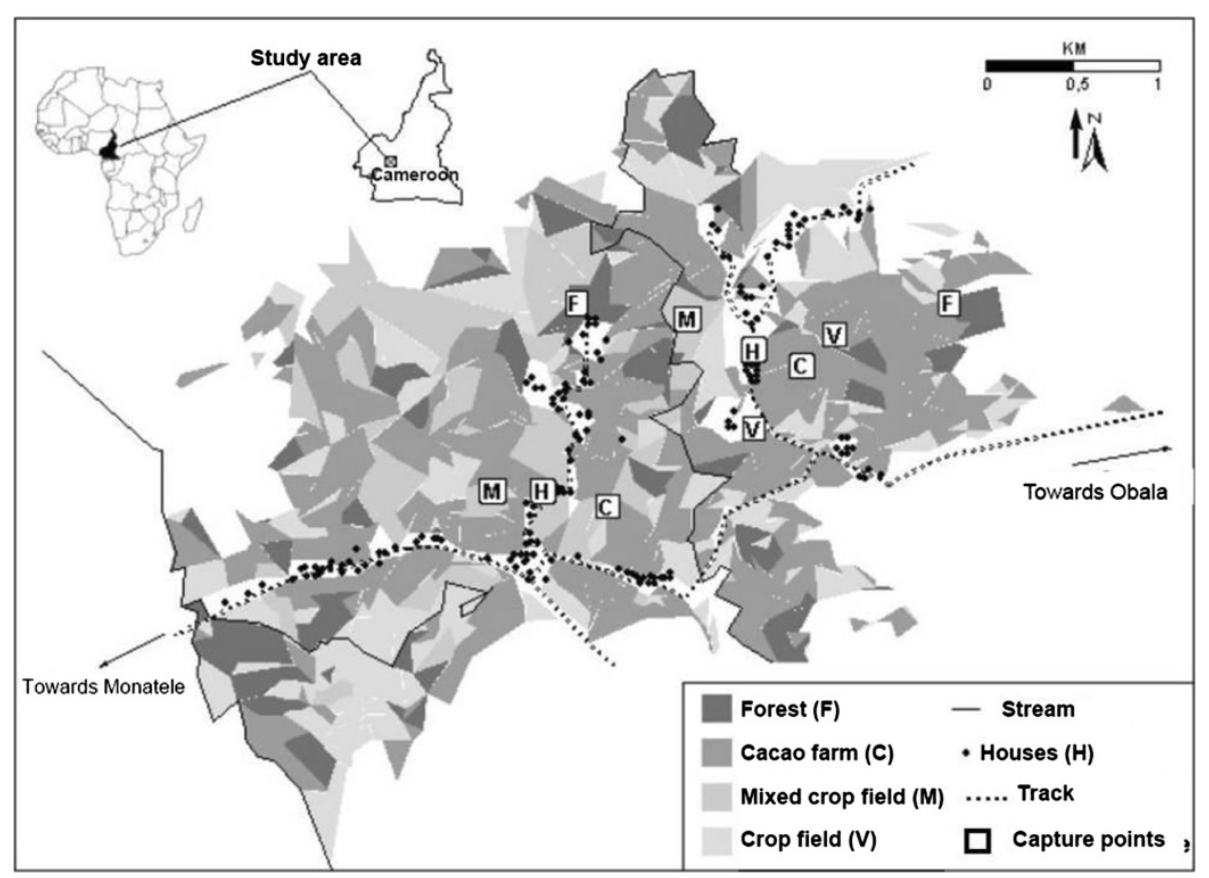

Figure 1 Map of Kokodo, with location of capture points (adapted from [16], with author's permission).

whether they had already received IVM treatment, and 107 (23.6\%) declared they had so (3 in 1993, 72 in 1994 and 32 in 1995). This relatively high proportion of persons already treated was due to the fact that largescale IVM treatments were organized since 1993 by the Ministry of Public Health and the non-governmental development organization (NGDO) Helen Keller International (HKI) in the neighboring sub-division of Monatele. After having been registered, all those persons aged 15 years and above and who had never taken IVM $(\mathrm{N}=69)$ were invited to provide blood by fingerprick to prepare blood smears to assess the prevalence and intensity of Loa microfilaremia. All the 453 volunteers received a single dose of IVM $(150 \mu \mathrm{g} / \mathrm{kg})$ just after sampling. Subsequent examination of the blood smears showed that the prevalence of Loa microfilaremia in the 69 ivermectin-naïve adults was $29.0 \%$ and the arithmetic mean microfilarial density among the microfilaremics was $10,401 \mathrm{mf} / \mathrm{ml}$.

In 1999, a second study was implemented in Kokodo whose objectives were (i) to characterize the transmission of L. loa by examining Chrysops caught over 12 months (May 1999-April 2000) in various places of the village [16] and (ii) to identify individual factors associated with the presence of Loa microfilaremia [17]. For the second part of the study, all residents aged $\geq 15$ years were again invited to be examined for Loa infection in April 1999, just before the first CDTI campaign launched by APOC in the area. Among the 441 who volunteered,
141 (32.0\%) declared they had received IVM after the 1996 study. The prevalence of Loa microfilaremia among the adults aged $\geq 15$ years who had not received IVM between 1996 and 1999 was 29.0\% (like in 1996) and the arithmetic mean microfilarial density among the microfilaremics was $8861 \mathrm{mf} / \mathrm{ml}$.

\section{Ivermectin treatment in Kokodo}

As mentioned above, Kokodo is not far from the border with the Monatele sub-division where large-scale IVM treatments have been organized from 1993 to 1998 by the Ministry of Public Health and HKI. Thus, a number of persons living in Kokodo could receive treatment during this period. Since 1999, Kokodo has been treated annually under the auspices of APOC, following the CDTI strategy. Drug coverages in the village itself are unknown for the years 1999-2006 but figures on the whole CDTI project ("Centre 3") were available for this period. For the years 2007-2010, coverage data on the village of Kokodo could be provided by the National Program for Onchocerciasis Control and HKI.

\section{Catches and dissection of Chrysops in 2012}

Catches were organized from 1 March to 30 June 2012, in exactly the same sites and conditions as in the first entomologic study [16]. This four-month period was chosen because it started and ended 6 and 10 months respectively, after the end of the previous CDTI campaign (August 2011). The captures were conducted 
in 10 catching stations located in 5 types of environment (forest, cacao farms, crop fields, mixed crop fields and inhabited areas). Two catching stations were chosen for each of these types, and catches of Chrysops were made every two weeks during three consecutive days. In this paper, data for all habitats were pooled for each study period. Flies were caught using hand nets from 07:00 to 18:00 by collectors stationed by a wood fire, the smoke of which attracts the flies $[18,19]$. One collector was allowed to catch between 7:00 and 12:00 and another one took over from 12:00 to 18:00. Each collector was rotated to a different caching station every day. The flies caught were put singly in a glass tube plugged with a cotton wool and grouped in bags labeled according to the catching station, environment type and hour. Bags were collected every two hours and brought back to the field laboratory where flies were first identified, then dissected alive after a slight knock down using a needle tip, and examined for parity and presence of $L$. loa larvae (first stage L1, second stage L2, and third stage L3 larvae). Dissection was carried out by a single individual. Identification of larvae was performed following the method of Orihel and Lowrie [20].

The head, thorax and abdomen were dissected separately. The infection rate was defined as the proportion of flies containing any larval stage (L1, L2 or L3), and the infective rate (IR) as the proportion of flies with L3s in the head or mouth parts. The potential infective rate (PIR) was considered as the proportion of dissected flies with L3 larvae, irrespective of their location in the fly. The infection and infective rates have been calculated using, first, the total number of flies, and then the number of parous flies, as the denominator. The mean head L3 load (MHL3) corresponded to the total number of L3s found in the head and mouth parts divided by the total number of Chrysops carrying L3s in this location. The mean fly L3 load (MFL3) was determined as the total number of flies with L3 larvae divided by the total number of flies with these larvae. The monthly transmission potential (MTP) was expressed as the number of infective larvae per man per month (L3/man/month), while the monthly biting density (MBD) was estimated as the mean number of fly bites per person per month (bites/man/month). The calculations of MBD and MTP were made using the formula used as part of studies on onchocerciasis transmission [21].

\section{Statistical analyses}

As mentioned above, the first entomologic study was conducted over 12 months, i.e. between 1 May 1999 and 30 April 2000. As the indicators of interest in this study (infection rate, IR, PIR, MHL3 and MFL3) fluctuate seasonally $[16,22-24]$, we decided to compare the figures obtained in 2012 with those obtained during the same months in 1999 and 2000 (March and April 2000, and May and June 1999). The non parametric Wilcoxon rank two-sample test was used to compare the MHL3 and MFL3 between 1999-2000 and 2012. Chi-square test was used to compare the infection rates, IR and PIR between the two periods. These comparisons were done on the infection and infective rates in the total number of Chrysops, and then on the rates in the parous flies only. Fischer's exact test was used in place of Chi-square test whenever the expected value was less than 5 . The significance level was set at 0.05 in all cases. All statistical analyses were performed using the STATA 12.1 software (STATA Corporation, College Station, TX, USA).

\section{Results}

\section{Entomologic indices}

During the initial study, the total numbers of Chrysops caught during the 4 month-period (March and April 2000, May and June 1999) was 982, and 976 of them were dissected (Table 1). C. silacea accounted for $85.2 \%$ of catches $(14.8 \%$ for $C$. dimidiata). The infection and infective rates did not differ significantly between both species $(\mathrm{p}=0.94$ and 0.89 , respectively). The MHL3 was higher for $C$. silacea than for $C$. dimidiata but due to the low number of infective $C$. dimidiata, the significance in the difference could not be computed. Of the

Table 1 Entomologic indices at baseline study (1999-2000)

\begin{tabular}{|c|c|c|c|c|c|c|c|c|c|c|c|c|c|c|c|c|c|c|c|}
\hline \multirow{2}{*}{$\begin{array}{l}\text { Study } \\
\text { period }\end{array}$} & & \multicolumn{3}{|c|}{ No. of chrysops caught* } & \multicolumn{3}{|c|}{ BD } & \multicolumn{3}{|c|}{ TP } & \multicolumn{3}{|c|}{ Infection rate (\%) } & \multicolumn{3}{|c|}{ Infective rate (\%) } & \multicolumn{3}{|c|}{ MHL3 load } \\
\hline & & $\mathrm{S}$ & D & $\mathrm{S}+\mathrm{D}$ & $\mathrm{S}$ & D & $S+D$ & $\mathrm{~S}$ & D & $S+D$ & $\mathrm{~S}$ & D & $S+D$ & $\mathrm{~S}$ & D & $S+D$ & $\mathrm{~S}$ & D & $S+D$ \\
\hline March & & 63 & 10 & 73 & 32.6 & 5.2 & 37.8 & 55.6 & 0.0 & 55.6 & 3.6 & 20.0 & 6.2 & 3.6 & 0.0 & 3.1 & 53.5 & 0.0 & 53.5 \\
\hline April & & 251 & 56 & 307 & 125.5 & 28.0 & 153.5 & 754.9 & 9.0 & 763.9 & 9.3 & 12.5 & 9.9 & 3.6 & 3.6 & 3.6 & 162.5 & 9.0 & 134.5 \\
\hline May & & 184 & 41 & 225 & 47.5 & 10.6 & 58.1 & 12.4 & 0.0 & 12.4 & 7.0 & 0.0 & 5.8 & 1.6 & 0.0 & 1.3 & 16.0 & 0.0 & 16.0 \\
\hline \multirow[t]{3}{*}{ June } & & 339 & 38 & 377 & 78.2 & 8.8 & 87.0 & 95.1 & 4.6 & 99.7 & 5.3 & 10.5 & 5.8 & 0.9 & 2.6 & 1.1 & 137.4 & 20.0 & 108 \\
\hline & Total & 837 & 145 & 982 & 283.8 & 52.6 & 336.4 & 918 & 13.6 & 931.6 & 6.7 & 9.0 & 7.1 & 2.1 & 2.1 & 2.1 & 119.4 & 12.7 & 103.4 \\
\hline & p-value & & - & - & & & - & - & & & & .94 & - & & & & - & & \\
\hline
\end{tabular}

${ }^{*}$ All the Chrysops were dissected except six C. silacea caught in March (2) and April (4); BD= biting densities; TP= transmission potential; MHL3= mean head L3 load; $\mathrm{S}=$ Chrysops silacea; $\mathrm{D}=$ Chrysops dimidiata; $\mathrm{S}+\mathrm{D}=$ both species combined. 
976 flies dissected, 27 (2.8\%) carried L3s (23 C. silacea and $4 \mathrm{C}$. dimidiata). The PIR was $2.8 \%$ for each of the two species. The MFL3 was $123 \mathrm{~L} 3 /$ fly for both species combined, and 141 and $18 \mathrm{~L} 3 /$ fly for $C$. silacea and $C$. dimidiata respectively.

Between March and June 2012, a total of 1559 Chrysops was caught and 1558 were dissected (Table 2). As previously observed in the baseline study, C. silacea was found to predominate, with a proportion of $92.9 \%$ of the Chrysops caught. Like in 1999-2000, the infection and infective rates were quite similar between both species ( $\mathrm{p}=0.94$ and 0.89 , respectively) and the MHL3 was higher in $C$. silacea than in $C$. dimidiata (again, the significance of the difference could not be computed due to the low number of infective $C$. dimidiata). Of the 1558 flies dissected, 33 (2\%) carried L3s (30 C. silacea and 3 C. dimidiata). The PIR were $2.0 \%$ and $2.8 \%$ for $C$. silacea and $C$. dimidiata respectively. The MFL3 were 122 and 121 L3/fly for C. silacea and C. dimidiata respectively, and $121 \mathrm{~L} 3 /$ fly for both species combined.

\section{Comparison of the entomologic indicators recorded in 1999-2000 and in 2012}

Results of comparisons are presented in Table 3. In the initial study, the infection and infective rates of $C$. silacea during the four months were 6.7 and $2.1 \%$, respectively, whereas in 2012, the same indicators for this species were $3.0 \%$ and $1.7 \%$ respectively. The infection rate for this species was significantly lower in 2012 than in 1999-2000 ( $\mathrm{p}=0.001)$. In contrast, the infective rates recorded during the two periods for this species did not differ significantly $(p=0.49)$. Similarly, the infection rate was significantly lower for C. dimidiata in 2012 than in the baseline study $(\mathrm{p}=0.04)$ while no significant difference in the IR for this species was reported between the two periods of investigation $(p=0.73)$. Considering both species pooled together, the infection rate in 2012 (3.0\%) was significantly lower than in the baseline study $(7.1 \%)(\mathrm{p}=0.001)$, while the infective rate
(1.7\% in 2012 and $2.1 \%$ in initial study) was not $(\mathrm{p}=0.55)$.

The PIRs recorded in the 2012 study were not significantly different from that recorded in 1999-2000 and this holds true either for $C$. silacea alone, or $C$ dimidiata alone, or both species combined $(\mathrm{p}=0.29,0.99$ and 0.30 respectively).

There was no significant difference in the MHL3 between the two investigation periods for $C$. silacea $(\mathrm{p}=0.91), C$. dimidiata $(\mathrm{p}=0.51)$, and both species combined $(p=0.91)$. Similarly, the difference in the MFL3 between the two studies was not significant for C. silacea $(\mathrm{p}=0.84), C$. dimidiata $(\mathrm{p}=0.48)$ or both species pooled together $(\mathrm{p}=0.55)$.

The biting density was almost three-fold higher in 2012 than in 1999-2000 for C. silacea but remained stable for $C$. dimidiata.

The transmission potential was higher in the present study than in the baseline investigation for each species or both species combined. There was a monthly variation in the transmission potential during both investigation periods (Tables 1 and 2).

The parous rate (Table 4) was significantly higher in the initial survey than in the second for $C$. silacea $(\mathrm{p}=0.00007)$ and both species combined $(\mathrm{p}=0.00001)$. As in the total Chrysops population dissected, there was a significant decrease in the infection rate for C. silacea and both species combined in parous fly population, from 19.4 and $20.1 \%$ respectively in the initial study to $11.1 \%$ in the present study ( $\mathrm{p}=0.002$ and 0.0005 respectively). Also, the infective and potential infective rates between the two periods for each species and for both species combined were not significantly different in parous flies.

\section{Drug coverage}

The drug coverages in the whole CDTI project area were $46 \%$ in $1999,29 \%$ in $2000,29 \%$ in $2001,50 \%$ in 2002 , $62 \%$ in $2003,67 \%$ in $2004,64 \%$ in 2005 , and $79 \%$ in 2006. For the following years, data was available at the

Table 2 Entomologic indices in the present investigation (2012)

\begin{tabular}{|c|c|c|c|c|c|c|c|c|c|c|c|c|c|c|c|c|c|c|c|}
\hline \multirow{2}{*}{$\begin{array}{l}\text { Study } \\
\text { period }\end{array}$} & & \multicolumn{3}{|c|}{ No of chrysops caught* } & \multicolumn{3}{|c|}{ BD } & \multicolumn{3}{|c|}{ TP } & \multicolumn{3}{|c|}{ Infection rate (\%) } & \multicolumn{3}{|c|}{ Infective rate (\%) } & \multicolumn{3}{|c|}{ MHL3 load } \\
\hline & & $\mathrm{S}$ & D & $\mathrm{S}+\mathrm{D}$ & $\mathrm{S}$ & D & $S+D$ & $\mathrm{~S}$ & D & $\mathrm{S}+\mathrm{D}$ & $\mathrm{S}$ & D & $\mathrm{S}+\mathrm{D}$ & $\mathrm{S}$ & D & $S+D$ & $\mathrm{~S}$ & D & $S+D$ \\
\hline March & & 282 & 42 & 324 & 213.9 & 39.3 & 253.2 & 572.5 & 0.0 & 572.5 & 3.9 & 2.4 & 3.7 & 2.5 & 0.0 & 2.2 & 100.7 & 0.0 & 100.7 \\
\hline April & & 270 & 31 & 301 & 136.0 & 17.0 & 153.0 & 204.6 & 0.0 & 204.6 & 3.3 & 0.0 & 3.0 & 2.2 & 0.0 & 2.0 & 67.7 & 0.0 & 67.7 \\
\hline May & & 584 & 26 & 610 & 303.8 & 15.5 & 319.3 & 30.2 & 17.3 & 47.5 & 2.1 & 11.5 & 2.5 & 0.9 & 11.5 & 1.3 & 11.6 & 9.7 & 10.9 \\
\hline \multirow[t]{3}{*}{ June } & & 313 & 11 & 324 & 157.0 & 7.0 & 164.0 & 352.0 & 0.0 & 352.0 & 3.5 & 0.0 & 3.4 & 1.9 & 0.0 & 1.9 & 117.3 & 0.0 & 117.3 \\
\hline & Total & 1449 & 110 & 1559 & 810.5 & 78.8 & 889.5 & 1159.3 & 17.3 & 1176.6 & 3.0 & 3.6 & 3.0 & 1.7 & 2.7 & 1.7 & 78.0 & 9.7 & 70.0 \\
\hline & p-value & \multicolumn{3}{|c|}{-} & \multicolumn{3}{|c|}{-} & \multicolumn{3}{|l|}{-} & \multicolumn{3}{|c|}{0.94} & \multicolumn{3}{|c|}{0.89} & \multicolumn{2}{|l|}{-} & \\
\hline
\end{tabular}

*All the Chrysops were dissected except one $C$. silacea caught in March; BD= biting densities; TP= transmission potential; MHL3= mean head L3 load. S= Chrysops silacea; $\mathrm{D}=$ Chrysops dimidiata; $\mathrm{S}+\mathrm{D}=$ both species combined. 
Table 3 Comparison of entomological indices between the two study periods (baseline study (1999-2000) and present investigation)

\begin{tabular}{|c|c|c|c|c|c|c|c|c|c|c|c|c|c|c|c|c|}
\hline \multirow{2}{*}{ Study period } & & \multicolumn{3}{|c|}{ Infection rate (\%) } & \multicolumn{3}{|c|}{ Infective rate (\%) } & \multicolumn{3}{|c|}{ Potential infective rate } & \multicolumn{3}{|c|}{ MHL3 load } & \multicolumn{3}{|c|}{ MFL3 load } \\
\hline & & $S$ & D & $S+D$ & $S$ & D & $S+D$ & $S$ & D & $S+D$ & $S$ & D & $S+D$ & $S$ & D & $S+D$ \\
\hline Baseline & & 6.7 & 9.0 & 7.1 & 2.1 & 2.1 & 2.1 & 2.8 & 2.8 & 2.8 & 119.0 & 13.0 & 103.0 & 141.0 & 18.0 & 123.0 \\
\hline 2012 & & 3.0 & 3.6 & 3.0 & 1.7 & 2.7 & 1.7 & 2.0 & 2.8 & 2.0 & 78.0 & 10.0 & 70.0 & 122.0 & 121.0 & 121.0 \\
\hline & p-value & 0.001 & 0.04 & 0.001 & 0.49 & 0.73 & 0.55 & 0.29 & 0.99 & 0.30 & 0.91 & 0.51 & 0.91 & 0.84 & 0.48 & 0.55 \\
\hline
\end{tabular}

NB: $\mathrm{S}=$ Chrysops silacea; $\mathrm{D}=$ Chrysops dimidiata; $\mathrm{S}+\mathrm{D}=$ both species combined; MHL3= mean head L3 load; MFL3= mean fly L3 load.

village level and the therapeutic coverage in Kokodo ranged from $67.9 \%$ in 2007 to $80.2 \%$ in 2010 , with values of $79.5 \%$ and $79.9 \%$ in 2008 and 2009 , respectively. Data related to 2011 were not available at the time of study.

\section{Discussion}

As in the initial study by Demanou and others [16], $C$. silacea and $C$. dimidiata were the only species caught during the investigation period, $C$. silacea being the predominating species. Previous studies showed that $C$. silacea was the dominating species in all Loa endemic areas in Cameroon except in the village of Ngat, $50 \mathrm{~km}$ south of Yaounde where $C$. dimidiata is the main vector of loiasis [15]. Our study confirmed that C. silacea is the most important vector in the Lekie area, both because of higher MHL3 (7.5- fold higher than in C. dimidiata), and of higher biting densities (10.3- fold higher than C. dimidiata biting densities).

IVM is an effective drug against O. volvulus, L. loa, Wuchereria bancrofti and is currently recommended and used by different global programs for the control of onchocerciasis and lymphatic filariasis. Regarding loiasis specifically, several studies showed that a single dose of IVM brings about a marked and long-standing decrease in Loa microfilaremia, lowers the prevalence of loiasis $[10,11]$, and reduces the infective rate of the Chrysops to low levels when given on a large scale at 3-monthly intervals [15]. Since large-scale administration of IVM was demonstrated to be an efficient means to control Loa transmission, it was hypothesized that CDTI would have had such a result in the Lekie division after several years of annual distributions. At the launching of CDTI in this division, entomologic data on the transmission of loiasis were recorded over 1 year, and distribution of IVM has been conducted annually, every year, with various therapeutic coverage rates. To evaluate the impact of this drug coverage on the transmission of loiasis, entomologic data were collected over a 4-month period from March to June 2012 and compared with the baseline data.

In 2012, the biting densities for $C$. silacea and $C$. dimidiata were 811 and 79 bites/man respectively for a 4- month study period, while for the same months and study duration in 1999-2000, these values were almost three-fold lower for $C$. silacea and nearly similar for $C$. dimidiata. Both species were shown to be sensitive to rainfall, but with a dominion of $C$. silacea over $C$. dimidiata in the rainy season [23]. The increase in the density of $C$. silacea but not $C$. dimidiata might be related to an increase in the rainfall in this area.

In the present study, we have used a number of indicators to evaluate the impact of CDTI on Loa transmission. As the infective forms of $L$. loa were suspected to be able to pass freely and fast from the head to the abdomen or vice-versa when the fly is feeding [25], flies carrying L3s were considered both when the latter were located in their head, or in other locations (thorax or abdomen). In spite of the significant reduction in Loa infection rate for each species (C. silacea and $C$. dimidiata) observed in 2012, the values of the IR, PIR, MHL3 and MFL3 recorded in 2012 were not significantly different from the initial values obtained in the baseline investigation for each species. The results were similar using both the total number of flies and the

Table 4 Comparison of infection, infective and potential infective rates in parous Chrysops between the two study periods

\begin{tabular}{|c|c|c|c|c|c|c|c|c|c|c|c|c|c|c|c|c|c|c|}
\hline \multirow[t]{2}{*}{ Study period } & \multicolumn{3}{|c|}{$\begin{array}{l}\text { No of chrysops } \\
\text { dissected }\end{array}$} & \multicolumn{3}{|c|}{$\begin{array}{l}\text { Number } \\
\text { parous }\end{array}$} & \multicolumn{3}{|c|}{$\begin{array}{l}\text { Percentage } \\
\text { parous (\%) }\end{array}$} & \multicolumn{3}{|c|}{$\begin{array}{l}\text { Infection rate } \\
\text { in parous (\%) }\end{array}$} & \multicolumn{3}{|c|}{$\begin{array}{l}\text { Infective rate } \\
\text { in parous (\%) }\end{array}$} & \multicolumn{3}{|c|}{$\begin{array}{l}\text { Potential infective } \\
\text { rate in parous }\end{array}$} \\
\hline & $\bar{S}$ & D & $S+D$ & $\bar{S}$ & D & $S+D$ & $\mathrm{~S}$ & D & $S+D$ & $\mathrm{~s}$ & D & $S+D$ & $\bar{S}$ & D & $S+D$ & $\bar{S}$ & D & $S+D$ \\
\hline Baseline & 831 & 145 & 976 & 289 & 55 & 344 & 34.5 & 37.9 & 35.2 & 19.4 & 23.1 & 20.1 & 5.9 & 5.5 & 5.8 & 8 & 7.3 & 7.8 \\
\hline \multirow[t]{2}{*}{2012} & 1448 & 110 & 1558 & 389 & 34 & 423 & 26.9 & 30.9 & 27.2 & 11.1 & 11.8 & 11.1 & 6.2 & 8.8 & 6.4 & 7.7 & 8.8 & 7.8 \\
\hline & & & & & & & 0.00007 & 0.24 & 0.00001 & 0.002 & 0.16 & 0.0005 & 0.87 & 0.53 & 0.74 & 0.90 & 0.79 & 0.98 \\
\hline
\end{tabular}


number of parous flies as the denominator. The stability in the values of these indices indicates that the level of exposure of $L$. loa has not changed after 13 years of treatment. Moreover, the intensity of infection remained high despite the significant drop observed in the infection rate. These surprising and disappointing observations could be attributed to several facts, some of which are: 1) the persistence of a significant parasite reservoir; 2 ) an increase in the density of vector flies; 3 ) the biting habits of the vector flies.

The parasite reservoirs are the microfilaria carriers, including the fraction of the population that remains untreated [26]. Among these individuals, some refuse to be treated by fear of SAEs. In this respect, it is worth noticing that in the past, the Lekie division had experienced many cases of SAEs [27]. In spite of the proper sensitization of populations through explanations of the advantages of taking IVM, reassurance about efficacy and safety about availability in health facilities of kits to manage possible SAE cases, some people are still reluctant to comply with the program. Other individuals who can act as reservoir are infected immigrants or former residents returning to the village from towns or areas where there is not treatment. A third group consists of residents remaining untreated due to shortage of drug during the CDTI campaign. Indeed, complaints on this issue were recorded by our team more than once in the field during Chrysops collection.

A second reason which may partly explain the limited impact of CDTI on entomologic indicators on Loa transmission is the increase in the density of Chrysops between 2000 and 2012. Whatever the reason(s) for this increase, this phenomenon increases the likelihood of a vector to bite an infected person and to pass on subsequently the infection to others, including healthy individuals.

Lastly, the biting behavior of Chrysops known as poolfeeding is very painful to the host. As a result, the fly usually bites multiple hosts in order to feed to repletion. This habit of multiplying the blood source increases the probability for the fly to feed on microfilaria carriers.

The fact that the infection rate was significantly reduced while the IR, PIR, MHL3 and MFL3 were not may be related to the reduction of parasite reservoir among the treated population for the first case, and to a phenomenon of "limitation" (where the parasite 'success rate' or 'yield' in the vector increases as the $\mathrm{mf}$ intake decreases) for the latter case. The parasite yield is high with Chrysops, as observed by Kershaw and Duke [28], and this might be due to the ability of Chrysops to live normally even when they harbor very high numbers of L3 $[28,29]$. However, there is little information on the type of relationships (limitation, facilitation or proportionality) between the number of Loa mf ingested by the
Chrysops and the number of infective larvae. This is due to the fact that, the Chrysops bites being painful, it is difficult to infect experimentally these vectors by making them feed on humans. However, Kershaw and Duke [28] found that "the number of infective forms found in flies which survive long enough to support the development of the infective forms is similar to the number of microfilariae taken in", suggesting the relationship is proportional. This does not explain the results obtained during the present study and should encourage conducting studies on this issue. Chrysops could be fed with blood from naturally infected human or from experimentally-infected baboons; in the latter case, blood meal could be taken directly on the host but in both cases, feeding could be made using a parafilm membrane technique [30].

In addition to these main facts, the therapeutic coverage as well as the duration of the treatment campaign within a year needs to be addressed. The official drug coverage from 2007 to 2010 ranged between 67.9 to $80.2 \%$. With such fairly high coverages, one might have expected a significant reduction in the transmission level of loiasis after more than a decade of drug administration, not a standstill [31]. Therefore, another explanation to the stability in the indicators might be that the therapeutic coverage reported might be overrated. External assessment of therapeutic coverage should be encouraged to validate or revise official figures. Since onchocerciasis and loiasis are co-endemic in the study area, and the parasite reservoir (human population) is the same for both O. volvulus and L. loa, the stability in the transmission level of loiasis despite several years of CDTI might also be found for onchocerciasis. This is supported by the results of recent epidemiological investigations on onchocerciasis in the neighboring health district Mbam valley, which showed that some villages still had very high prevalences of O. volvulus infection ( $>50 \%)$ in spite of 15 rounds of annual CDTI (Boussinesq et al., unpublished data). The authorities in charge of onchocerciasis control program should consider the results of the present investigation for the better management of their activities in that area. Also, epidemiological studies on $L$. loa transmission in the Lekie division are necessary to complement this work.

\section{Conclusion}

In conclusion, this study showed that the transmission of loiasis in the Lekie division is still active, as suggested by the infection rate remaining high, the high TP and the stability observed in the IR, PIR, MHL3 and MFL3 after 13 years of CDTI. This is an indication that the risk of occurrence of severe adverse events such as fatal encephalopathies is still present, especially for heavily microfilaria-loaded people taken ivermectin for the first time. Complementary data on the level of Loa microfilaremia are needed in the area. 


\section{Competing interests}

The authors declare that they have no competing interests.

\section{Authors' contributions}

All the authors have contributed significantly to this study. MKK, MB and JK contributed intellectually to the conceptualization and design of the study. JB T-M performed the statistical analysis. MKK and MD carried out the laboratories and field studies. MKK, MB, SDP and JK prepared the manuscript. All authors read and approved the final manuscript.

\section{Acknowledgements}

This study was partly funded by the Filariases and other Tropical Diseases Research Center (CRFILMT) supported by Mectizan Donation Program (MDP). It was also funded by APOC through financial support for the training of MKK in entomology in Benin. Dr Raceline Gounou is duly acknowledged for providing some dissecting materials. Mr. Guerin Moudze and Mrs. Sintiche Madjo Amougou are very much appreciated for their logistic help. The support of the chief, volunteers and the entire population of Kokodo are highly acknowledged.

\section{Author details}

${ }^{1}$ Filariases and other Tropical Diseases Research Center (CRFilMT), P.O. Box 5797, Yaoundé, Cameroon. ' Department of Animal Production, University of Dschang, P.O. Box 222, Dschang, Cameroon. ${ }^{3}$ Centre Pasteur of Cameroon, P.O. Box 1274, Yaoundé, Cameroon. Institut de Recherche pour le Développement (IRD), P.O. Box 64501, Montpellier, France. ${ }^{5}$ Université de Montpellier 1, 5 Boulevard IV, Montpellier 34000, France. ${ }^{6}$ Faculty of Medicine and Biomedical Sciences University of Yaoundé I, P.O. Box 1364, Yaoundé, Cameroon.

Received: 9 May 2013 Accepted: 25 September 2013

Published: 27 September 2013

\section{References}

1. Boussinesq M, Gardon J, Gardon-Wendel N, Chippaux JP: Clinical picture, epidemiology and outcome of Loa-associated serious adverse events related to mass ivermectin treatment of onchocerciasis in Cameroon. Filaria J 2003, 2(Suppl 1):S4.

2. Boussinesq M, Gardon J, Gardon-Wendel N, Kamgno J, Ngoumou P, Chippaux JP: Three probable cases of Loa loa encephalopathy following ivermectin treatment for onchocerciasis. Am J Trop Med Hyg 1998, 58:461-469

3. Chippaux JP, Boussinesq M, Gardon J, Gardon-Wendel N, Ernould JC: Severe adverse reaction risks during mass treatment with ivermectin in loiasis-endemic areas. Parasitol Today 1996, 12:448-450.

4. Gardon J, Gardon Wendel N, Demanga N, Kamgno J, Chippaux JP, Boussinesq M: Serious reactions after mass treatment of onchocerciasis with ivermectin in an area endemic for Loa Loa infection. Lancet 1997a, 350(9070):18-22.

5. Boussinesq M, Gardon J: Prevalences of Loa loa microfilaraemia throughout the area endemic for the infection. Ann Trop Med Parasitol 2005, 91:573-589.

6. Zoure HGM, Wanji S, Noma M, Amazigo UV, Peter J, Diggle PJ, Tekle AH, Remme JHF: The Geographic Distribution of Loa loa in Africa: Results of Large-Scale Implementation of the Rapid Assessment Procedure for Loiasis (RAPLOA). Plos Negl Trop Dis 2011, 5:e1210.

7. Alleman MM, Twum-Danso NAY, Thylefors Bl: The Mectizan ${ }^{\circledast}$ Donation Program - highlights from 2005. Filaria J 2006, 5:11.

8. Anonymous: Report of a Scientific Working Group on Serious Adverse Events following Mectizan ${ }^{\circledR}$ treatment of onchocerciasis in Loa loa endemic areas, Scientific Working Group on Serious Adverse Events in Loa Loa endemic areas. Filaria J 2003, 2(Suppl 1):S2.

9. Haselow NJ, Julie Akame J, Evini C, Akongo S: Programmatic and communication issues in relation to serious adverse events following ivermectin treatment in areas co-endemic for onchocerciasis and loiasis. Filaria J 2003, 2(Suppl 1):S10.

10. Duong TH, Kombila M, Ferrer A, Bureau P, Gaxotte P, Richard-Lenoble $D$ : Reduced Loa loa microfilaria count ten to twelve months after a single dose of ivermectin. Trans R Soc Trop Med Hyg 1997, 91:592-593.
11. Gardon J, Kamgno J, Folefack G, Gardon-wendel N, Bouchité B, Boussinesq M: Marked decrease in Loa loa microfilaraemia six and twelve months after a single dose of ivermectin. Trans R Soc Trop Med Hyg 1997, 91:593-594.

12. Kamgno J, Sodahlon Y, Ogoussan K, Tukov DN, Ntep M, Klion A, Boussinesq M, Mackenzie C, Hopkins A: incidence and geographical distribution of serious adverse events following mass administration of ivermectin in cameroon from 1999 to 2009. Am J Trop Med Hyg 2011, 85(Suppl):178.

13. Richardson ET, Luo R, Fink DL, Nutman TB, Geisse JK, Barry M: Transient facial swellings in a patient with a remote African travel history. J Trav Med 2012, 19:183-185.

14. Boussinesq M, Prod'hon J, Chippaux JP: Onchocerca volvulus: striking decrease in transmission in the Vina valley (Cameroon) after eight annual large scale ivermectin treatments. Trans R Soc Trop Med Hyg 1997, 91:82-86.

15. Chippaux JP, Bouchite B, Boussinesq M, Ranque S, Baldet T, Demanou M: Impact of repeated large scale ivermectin treatments on the transmission of Loa loa. Trans Roy Soc Trop Hyg 1998, 92:454-458.

16. Demanou M, Pion SDS, Boussinesq M: Étude entomologique sur la transmission de la loase dans le département de la Lékié (Cameroun). Bull Soc Pathol Exot 2001, 94:347-352.

17. Pion SDS, Demanou M, Oudin B, Boussinesq M: Loiasis: the individual factors associated with the presence of microfilaraemia. Ann Trop Med Parasit 2005, 99:491-500.

18. Caubère $P$, Noireau F: Effect of attraction factors on the sampling of Chrysops silacea and C. dimidiata (Diptera: Tabanidae), vectors of Loa loa (Filaroidea: Onchocercidae) filariasis. J Med Entomol 1991, 28:263-265.

19. Duke BOL: Studies on the biting habits of Chrysops. II. The effect of wood fires on the biting density of Chrysops silacea in the rain-forest at Kumba, British Cameroons. Ann Trop Med Parasitol 1955, 49:260-272

20. Orihel TC, Lowrie RC: Loa loa: development to the infective stage in an american deerfly, Chrysops atlanticus. Am J Trop Med Hyg 1975, 24:610-615.

21. Walsh JF, Davies JB, Le Berre R, Garms R: Standardization of criteria for assessing the effect of Simulium control in onchocerciasis control programmes. Trans R Soc Trop Med Hyg 1978, 72:675-676.

22. Duke BOL: Study on the biting habit of Chrysops: a comparison of the biting habit, monthly biting densities and infection rates of $C$. silacea and C. dimidiata (Bombe form) in the rain forest at Kumba, Southern Cameroon, U.U.K.A. Ann Trop Med Parasitol 1959, 53:203-214

23. Noireau F, Nzoulani A, Sinda D, Itoua A: Chrysops silacea and C. dimidiata: fly densities and infection rates with Loa loa in the chaillu mountains, congo republic. Trans R Soc Trop Med Hyg 1990, 84:153-155.

24. Wanji S, Tendongfor N, Eyong M, Enyong P: Chrysops silacea biting densities and transmission potential in an endemic area of human loiasis in south-west Cameroon. Trop Med Int Hith 2002, 7:371-377.

25. Gordon RM, Crewe W: The deposition of the infective stage of Loa loa by Chrysops silacea, and the early stages of its migration to the deeper tissues of the mammalian host. Ann Trop Med Parasitol 1953, 47:74-87.

26. Brieger WR, Okeibunor JC, Abiose AO O, Wanji S, Elhassan E, Ndyomugyenyi $R$, Amazigo UV V: Compliance with eight years of annual ivermectin treatment of onchocerciasis in Cameroon and Nigeria. Parasit Vectors 2011, 4:152.

27. Twum-Danso NAY: Serious adverse events following treatment with ivermectin for onchocerciasis control: a review of reported cases. Filaria J 2003, 2(Suppl 1):S3.

28. Kershaw WE, Duke BOL: Studies on the intake of microfilariae by their insect vectors, their survival, and their effect on the survival of their vectors. V. The survival of Loa loa in Chrysops silacea under laboratory conditions. Ann Trop Med Parasit 1954, 48:340-344.

29. Kershaw WE, Chalmers TA, Duke BOL: Studies on the intake of microfilariae by their insect vectors, their survival, and their effect on the survival of their vectors. IV. The survival-rate of Chrysops under laboratory conditions, and the effect upon it of Loa loa. Ann Trop Med Parasit 1954, 48:329-339. 
30. Downer KE, Stoffolano JJG: The effect of octenol on engorgement by the salt marsh horse fly, Tabanus nigrovittatus Macquart (Diptera: Tabanidae). J Med Entomol 2006, 43:643-645.

31. Tekle AH, Elhassan E, Isiyaku S, Amazigo UV, Bush S, Noma M, Cousens S, Abiose A, Remme JH: Impact of long-term treatment of onchocerciasis with ivermectin in Kaduna State, Nigeria: first evidence of the potential for elimination in the operational area of the African Programme for Onchocerciasis Control. Parasit Vectors 2012, 5:28.

doi:10.1186/1756-3305-6-283

Cite this article as: Kouam et al:: Impact of repeated ivermectin treatments against onchocerciasis on the transmission of loiasis: an entomologic evaluation in central Cameroon. Parasites \& Vectors 2013 6:283

\section{Submit your next manuscript to BioMed Central and take full advantage of:}

- Convenient online submission

- Thorough peer review

- No space constraints or color figure charges

- Immediate publication on acceptance

- Inclusion in PubMed, CAS, Scopus and Google Scholar

- Research which is freely available for redistribution 